\title{
ARISTÓTELES E EDUCAÇ̃̃O ESCOLAR: UM EXAME FILOSÓFICO SOBRE O CAMPO ACADÊMICO DO CURRÍCULO
}

\author{
ARISTÓTELES Y EDUCACIÓN ESCOLAR: UN EXAMEN FILOSÓFICO \\ SOBRE EL CAMPO ACADÉMICO DEL CURRÍCULO
}

\section{ARISTÓTELES AND SCHOOL EDUCATION: A PHILOSOPHICAL EXAM ON THE ACADEMIC FIELD OF THE CURRICULUM}

\author{
Marcos Vinicius Marques \\ Mestre em Educação pela Universidade Estadual Paulista "Júlio de Mesquita Filho" \\ Membro do GEPEFEC - UNESP- Araraquara \\ E-mail: vinny_educa@hotmail.com
}

\begin{abstract}
RESUMO
O tema deste artigo são as discussões atuais sobre o currículo escolar. Duas visões sobre o mesmo tema foram analisadas filosoficamente com base em alguns elementos presentes na obra aristotélica: A primeira diz respeito à influência do contexto de atuação profissional na configuração curricular; A segunda se refere ao multiculturalismo, como referencial que ganha cada vez mais aceitação nas pesquisas atuais sobre o tema. As relações entre estas duas formas de conceber as pesquisas acadêmicas sobre o currículo foram analisadas a partir da demonstração de alguns princípios presentes na obra de Aristóteles. A partir deste exame filosófico, defendemos que, para que os estudos sobre currículo promovam ações mais eficazes é necessário passarmos a considerar, cada vez mais, o contexto de atuação profissional a fim de tornarmo-nos mais eficazes na tarefa de ensinar.
\end{abstract}

Palavras-chaves: Currículo; Filosofia; Aristóteles.

\section{RESUMEN}

El tema del artículo son las discusiones actuales sobre el currículo escolar. Dos visiones sobre el tema fueron analizadas filosóficamente con base en algunos elementos presentes en la obra aristotélica: La primera se refiere a la influencia del contexto del profesional en la definición de un currículo; La segunda se refiere al multiculturalismo, como referencial que se vuelve cada vez más importante cuando se trata de investigación sobre el tema. Las relaciones entre las dos formas de concebir investigación académica o currículo fueron analizadas a partir de la demostración de algunos principios presentes en la obra de Aristóteles. A partir de esta perspectiva filosófica, defendemos que, para que se pueda mantener acciones más eficaces acerca del currículo es necesario que se considerare cada vez más el contexto del desarrollo profesional para llegar a ser más efectivos en la enseñanza.

Palabras claves: Currículo; la filosofía; Aristóteles

\section{ABSTRACT}

The theme of this article are the current discussions on the school curriculum. Two views on the same theme were analyzed philosophically based on some elements present in Aristotle's work: The first relates to the influence of professional context in curricular setting; The second refers to multiculturalism, as a reference which acquire more and more acceptance in 
the current research on the topic. The relationships between these two ways of understanding the academic research on the curriculum have been analyzed from the demonstration of some principles present in the work of Aristotle. From this philosophical examination, we argue that, for the studies curriculum promote more effective action is necessary to consider, more and more, the professional performance in context in order to become more effective in the task of teaching.

Keywords: Curriculum; philosophy; Aristotle.

\section{INTRODUÇÃO}

O presente trabalho se configura como uma análise filosófica de algumas questões levantadas nas discussões sobre o currículo escolar. Nosso objetivo foi demonstrar alguns princípios filosóficos necessários para o aprofundamento das discussões acadêmicas sobre o currículo escolar.

Arroyo (2011, p. 13) define o currículo como "o núcleo e o espaço central mais estruturante da função da escola. Por causa disso é o território mais cercado, mais normatizado. Mas também o mais politizado, inovado e ressignificado”. E, segundo Gimeno e Pérez (1998, p.126):

O conceito de currículo é bastante elástico; poderia ser qualificado de impreciso porque pode significar coisas distintas segundo o enfoque que o desenvolva, mas a polissemia também indica riqueza neste caso porque, estando em caso elaboração conceitual, oferece perspectivas diferentes sobre a realidade do ensino.

Dada esta importância do currículo escolar, bem como a complexidade do assunto, é necessário esclarecermos o lugar teórico que nos orienta, bem como o foco que daremos aqui. Destacamos, portanto que, para nós, é fundamental o entendimento de currículo como um processo de grande complexidade - a qual se deve à participação e intervenção de vários sujeitos/organizações/variáveis nas diversas fases em que o mesmo se configura. Por isso, é importante que, ao longo do trabalho, entenda-se o termo currículo a partir de uma visão processual, conforme a definição de Gimeno (2000, p. 102), que o delimita como

um objeto que se constrói no processo de configuração, implantação, concretização e expressão de determinadas práticas pedagógicas e em sua própria avaliação, como resultado das diversas intervenções que nele se operam. 
Tendo em vista esta delimitação sobre o que vem a ser o currículo, nos proporemos a abordar dois aspectos intrinsecamente necessários para embasar nossa discussão: Primeiro: As relações entre currículo e contexto; Segundo: O enfoque dado atualmente pelas pesquisas sobre currículo e Educação Física, ou seja, o enfoque multicultural.

\section{DESENVOLVIMENTO}

\subsection{Currículo e contexto}

É essencial que, ao discutir o tema do currículo, discutamos também aspectos ligados ao contexto em que o mesmo se insere, uma vez que, além do compromisso de seleção da cultura (GIMENO, 2000), o currículo, como núcleo da educação escolar, é o elemento responsável também pela transmissão desta mesma cultura. Esta transmissão, por sua vez, está ligada às práticas pedagógicas adotadas para o ensino, as quais, como condição para sua eficácia, necessitam estar adaptadas ao contexto escolar em que o currículo se configura. Neste sentido, ressaltamos que pensar sobre o currículo exige também que consideremos o compromisso com a reelaboração didática de acordo com o contexto, a fim de que os conteúdos - frutos da seleção cultural - sejam, de fato, ensinados de forma eficaz às novas gerações (FORQUIN, 1993). Segundo este autor:

A educação não se limita a fazer uma seleção entre os saberes e os materiais culturais disponíveis num dado momento, ela deve também, para torná-los efetivamente transmissíveis, efetivamente assimiláveis às novas gerações, entregar-se a um imenso trabalho de reorganização, de reestruturação, ou de transposição didática. (p. 16)

A partir da importância das práticas pedagógicas para o processo de configuração curricular, devemos lembrar que essas não se dão de forma independente, mas que sofrem influências diversas do contexto. Por isso, de acordo com Gimeno (2000, p. 90), a construção do currículo

não pode ser entendida separadamente das condições reais do seu desenvolvimento e, por isso mesmo, entender o currículo num sistema educativo requer prestar atenção às práticas políticas e administrativas que se expressam em seu desenvolvimento, às condições estruturais, organizativas, materiais, dotação de professorado, à bagagem de ideias e significado que lhe dão forma e que o modelam em sucessivos passos de transformação 
Deste fator também advém importância da consideração do contexto de atuação dos professores no processo de elaboração dos trabalhos acadêmicos sobre educação escolar. Neste sentido, Tardif e Lessard (2012, p. 23-24), nos alertam sobre "o perigo que ameaça a pesquisa sobre a docência e, mais amplamente, toda pesquisa sobre educação". Segundo eles, existe

o perigo da abstração: elas [as pesquisas] se fundamentam a mais das vezes sobre abstrações - a pedagogia, a didática, a tecnologia do ensino, o conhecimento, a cognição, a aprendizagem, etc. - sem levar em consideração fenômenos como o tempo de trabalho dos professores, o número de alunos, suas dificuldades e suas diferenças, a matéria a cobrir e sua natureza, os recursos disponíveis, as dificuldades presentes, a relação com os colegas de trabalho, com os especialistas, os conhecimentos dos agentes escolares, o controle da administração, a burocracia, a divisão e a especialização do trabalho, etc.

$\mathrm{Na}$ tentativa de diminuição do espaço encontrado entre as pesquisas e o trabalho do professor, no presente trabalho, valorizamos justamente a relação entre o contexto de atuação profissional e a influência do mesmo sobre a configuração do currículo e das práticas pedagógicas, as quais tem sido um elemento um tanto quanto desprezado nas pesquisas atuais sobre o tema do currículo e da Educação Física. (MARQUES, 2014)

\subsection{Currículo pós-crítico (multiculturalismo)}

As teorias pós-críticas do currículo têm como base o movimento do pós-modernismo e como características fundamentais a contestação da ideia de teorias (definições) do currículo teorias tradicionais e críticas - e a defesa do chamado multiculturalismo. Segundo Lopes e Macedo (2011), até meados de 1990, não havia estudos curriculares que estavam respaldados nas discussões das teorias pós-críticas do currículo. Foi no início deste século, com os estudos de Tomaz Tadeu da Silva (importante representante na constituição deste movimento), que os mesmos ganharam maior relevância acadêmica. Concordando com as ideias pós-modernistas, Silva (2011, p. 14) argumenta que: "Uma definição não nos revela o que é, essencialmente, o currículo: uma definição nos revela o que uma determinada teoria pensa o que o currículo é.” E, ainda, sobre o respeito às diferenças culturais (multiculturalismo):

Os diferentes grupos culturais se tornariam igualados por sua comum humanidade [...] É em nome desta humanidade comum que esse tipo de multiculturalismo apela para o respeito, a tolerância e a convivência pacífica 
entre as diferentes culturas. Deve-se tolerar e respeitar a diferença porque sob a aparente diferença há uma mesma humanidade. (p. 86)

Ainda sobre os estudos multiculturalistas Silva (2011, p. 90) também argumenta:

O multiculturalismo mostra que o gradiente da desigualdade em matéria de educação e currículo é função de outras dinâmicas, como as de gênero, raça, sexualidade, por exemplo, que não podem ser reduzidas à dinâmica de classe. Além disso, o multiculturalismo nos faz lembrar que a igualdade não pode ser obtida simplesmente através da igualdade de acesso ao currículo hegemônico existente, como nas reivindicações educacionais progressistas anteriores. A obtenção da igualdade depende de uma modificação substancial do currículo existente. (p. 90)

Faz-se necessário desde já um esclarecimento sobre nosso posicionamento teórico: Apesar de concordarmos com algumas ideias, como por exemplo, a importância de se considerar os aspectos culturais, bem como sua influência na configuração do currículo escolar, ainda questionamos alguns aspectos deste tipo de estudo (multiculturalista). As pesquisas que trabalham com este viés, na maioria das vezes, por almejar que todo tipo de cultura esteja abarcado no currículo, acabam relativizando-o em demasia. Desta forma, inevitavelmente, relativizam o próprio conhecimento humano e universal, o qual tem seu valor estabelecido (para o ensino) acima das particularidades e peculiaridades de cada grupo social (FORQUIN, 2000). Há aqui uma inversão clara na ordem do pensamento: De um preceito metodológico, passamos a uma regra ontológica. Segundo Carvalho (1994, n.p.): "Um preceito metodológico ensina como você deve investigar as coisas; um princípio ontológico estabelece como as coisas realmente são".

Neste caso, é como se aquilo que, inicialmente, era uma técnica metodológica para a investigação da realidade, que objetivava apenas a melhora na eficácia das práticas e dos instrumentos pedagógicos, deixando de ser técnica, com o multiculturalismo, passasse a ser agora um princípio, ao mesmo tempo em que de ordem metodológica se tornasse algo ordem ontológica e, assim, irrevogável. É desta maneira que a consideração das diferenças passa ao relativismo, bem como a consideração da cultura se torna o multiculturalismo, no sentido mais negativo do termo: "Sempre que passamos do preceito metodológico para o princípio ontológico existe, no mínimo, uma imprudência muito grande” (n.p.)

Por isso, partindo-se deste princípio (multiculturalismo), nega-se a ideia da existência de conteúdos universais. Neste ponto discordamos totalmente das teorias pós-críticas. Segundo Forquin (2000, p.62): "É preciso ensinar certas coisas em vez de outras e ensiná-las como válidas e valendo para todos e não somente para um determinado grupo". Sobre esta 
questão do relativismo, frente à importância do caráter universal e necessário de certos conteúdos, o mesmo autor discorre:

\footnotetext{
No contexto das sociedades multiculturais contemporâneas, se é verdade que a escola não pode mais ignorar a diversidades dos públicos a ela confiados, também é verdade que só poderá desempenhar de modo coerente sua tarefa de formação intelectual e de integração cívica e simbólica se repudiar a tentação do relativismo. (p.63)
}

Esta tendência multiculturalista é, como vimos acima, uma ideia recente para a área da Educação. De, qualquer forma, tem tomado cada vez mais os espaços de discussão sobre o currículo.

\subsection{Princípios filosóficos e caminho metodológico}

Até aqui nos empenhamos em apresentar dois tipos de discussões sobre currículo: Uma trata do tema partir de uma abordagem multicultural, enquanto a outra adota como viés a valorização das influências do contexto de atuação profissional sobre as práticas pedagógicas, as quais estão ligadas intimamente ao currículo - à medida que o mesmo é encarado como um processo. Estes dois enfoques, aparentemente, parecem ser apenas duas formas distintas de olhar a mesma coisa. Porém, há imbricados nesta distinção alguns princípios fundamentais, os quais, a nosso ver, podem ser demonstrados pela discussão filosófica, a partir de alguns elementos específicos presentes na obra de Aristóteles. Buscamos, assim, apresentar as bases necessárias, através das quais seja facilitado o entendimento das discussões atuais sobre o tema.

Dando prosseguimento à discussão, após as delimitações das posições acima evidenciadas, exporemos alguns princípios filosóficos de cunho aristotélico, os quais possibilitarão uma nova análise sobre o tema. A escolha deste viés é justificada pela riqueza deste pensamento - atualmente pouco aproveitado e, quando utilizado, mal interpretado (CARVALHO, 1997). “Aristóteles, com seu colossal bom senso, talvez tenha sido o maior dos filósofos; com certeza o mais prático de todos os filósofos.” (CHESTERTON, 2007, p. 132)

\subsection{Platão, Aristóteles e a revolução}


Contextualizemos brevemente o pensamento de Aristóteles, a partir do pensamento de Platão: Este foi mestre daquele. Aristóteles chegou até a exercer o cargo de professor na Academia (lugar fundado por Platão para a divulgação de suas ideias). Apesar desta relação e da equivalente grandeza destes dois filósofos (ambos foram capazes de influenciar toda história do pensamento ocidental), encontramos diferenças significativas entre os dois. (SANTOS, 1961; CARVALHO, 1994; REALE; ANTISERI, 2007). Destacaremos algumas aqui, as quais estão diretamente relacionadas com nossa proposta para este trabalho.

De acordo com Carvalho (1994), Platão, de origem grega e nobre, viveu numa época de grande caos moral. Este fator o estimulou a ter ideias que visassem a possibilidade de dar ordem àquilo que estava desordenado - este princípio tem sua origem na geometria, ciência altamente desenvolvida e valorizada em sua época. Segundo o autor acima citado, Platão "sempre tentou interferir na política, tentou reformar o mundo, inspirou revolução e golpes de Estado" e, em uma de suas obras, "declara que a obra de sua vida seria uma reforma política da Grécia" (CARVALHO, 1994, n.p.). Neste ponto, difere em muito de Aristóteles: Este era de origem estrangeira em relação ao meio ateniense (natural de Estagira, uma colônia macedônica), o que lhe impedia de participar da política. Não era membro da nobreza. Era de uma família de médicos, os quais, na época, não gozavam de tanto prestígio, comparados com o dos nobres atenienses.

Enquanto Aristóteles tinha como principal objetivo de vida o conhecimento filosófico, Platão se configurava como uma "mistura de filósofo e estadista" (n.p.). Esta característica de Platão é fundamental para entender seu pensamento. Ele almejava dar ordem ao caos do mundo sensível e acreditava que a separação entre esse mundo e o mundo das ideias possibilitaria que o ser humano que tivesse acesso ao mundo verdadeiro, o mundo das ideias o que só é possível àqueles que se ocupam das atividades exclusivamente racionais, ou seja, aos filósofos - pudesse, depois deste conhecimento da perfeição, dar ordem ao caos em que se encontra o mundo sensível, o tornando, assim, mais perfeito à medida que se assemelha ao das ideias. De acordo com Reale e Antiseri (2007, p. 141): "Platão pretendeu sustentar o seguinte: o sensível só explica mediante o recurso ao supra-sensível, o relativo com o absoluto, o móvel com o imóvel, o corruptível com o eterno."

Concordamos com Carvalho (1994), que afirma que nesta forma de pensar se encontra um dos principais equívocos de Platão. Segundo o autor, Platão, argumentando assim, acaba criando um "mundo filosófico" apartado da realidade, a qual apresenta-se para 
ele como algo negativo e digno de desprezo filosófico. Deste modo, é inevitável que se crie um sistema de pensamento marcado

por um abstratismo, uma geometrização e uma absolutização da divisão do mundo em dois estratos. Em parte, essa mudança na orientação da filosofia de Platão acontece por força destas experiências que mostram ao filósofo o caráter rebelde do caos do mundo, que não se curva tão facilmente aos nossos impulsos reformadores.

De acordo com a tese de Carvalho (1994), assim como a filosofia de Platão pode ter sido influenciada por esta tendência política marcante de sua vida, podemos supor que a vida de Aristóteles, mais especificamente o fato de ter sido filho de um médico, o influenciou a ter um apreço mais pelos aspectos biológicos e fisiológicos das ciências, do que pelas ciências matemáticas e geométricas, como o tinha Platão. Podemos perceber isso pelo caráter organicista que Aristóteles dá a sua filosofia, na qual o filósofo defende que não podemos separar o mundo em real e ideal, bem como não podemos separar o singular do universal. O verdadeiro conhecimento e, consequentemente, a possibilidade de promover qualquer mudança, advém então, não de uma separação, mas sim de uma tensão. São tão diferentes quanto o são a vida e a morte. Segundo Carvalho (1994, n.p.),

A primeira coisa que se observa num organismo é a inseparabilidade que existe entre a unidade e a variedade que o compõe. O organismo tem característica de morrer se for cortado pelo meio. Se perder a unidade, já não existe mais. Por outro lado, é uma unidade composta de uma diversidade, de uma diversificação muito grande de órgãos - por isso mesmo se chama organismo (conjunto harmônico de órgãos que funciona para o mesmo fim) [...] Esta harmonia é própria da integridade do corpo humano. Quando os órgãos se rebelam uns contra os outros é a doença, e em seguida a morte. Quando o organismo morre, ele se decompõe, suas partes mínimas separamse e ele adquire vida autônoma.

Poderíamos aqui continuar a análise das diferenças entre estes dois gigantes da filosofia, porém chamamos a atenção para dois aspectos evidenciados, os quais dizem respeito aos erros de Platão e a solução para os mesmos presentes em Aristóteles: Primeiro, a separação entre mundo real e mundo ideal em Platão em oposição à organicidade observada na tensão entre idealidade e realidade presente em Aristóteles (Unidade na variedade), sobre os quais discorreremos mais a frente; Segundo, a ideia de luta e revolução, marcante em Platão e ausente em Aristóteles.

Fazendo uma analogia com o tema do currículo, podemos dizer que a revolução tem sido, assim como neste aspecto da vida de Platão, a marca fundamental das teorias acerca do 
tema na atualidade. Defendemos que a tematização do currículo, visto como um processo complexo - devido à participação e intervenção de vários sujeitos/organizações/variáveis nas diversas fases em que o mesmo se configura - exige sempre uma visão orgânica, na qual todos os aspectos devem ser considerados, a fim de que seja possível qualquer tentativa de melhora. Deste modo, consideramos os singulares (as diferentes práticas pedagógicas adequadas aos contextos de atuação profissional específicos), sem perder de vista a função unificadora do currículo, ligada à universalidade do ensino dos conteúdos.

Platão quis dar harmonia aos caos da realidade através do mundo das ideias, ou das ideias que tinha sobre o mundo, da mesma forma que, para nós, os multiculturalistas almejam resolver o problema da sociedade e da escola por ideias que têm sobre a atualidade e o currículo escolar. Para tentar resolver alguns problemas do mundo, Platão concebe a existência de dois mundos: "Como se o mundo da nossa experiência, aquele sobre o qual investigamos, já não fosse bastante complicado, você cria dois mundos" (CARVALHO, 1994, n.p.). Da mesma forma, os multiculturalistas, ao invés de tentarem resolver os conflitos já existentes no chão da escola, através do incentivo exagerado que fazem às lutas e revoluções sócio-culturais, criam outros inúmeros problemas, que, a partir de então, a escola também teria que passar lidar, correndo risco de perder até as conquistas positivas que já havia alcançado. Para nós, esses problemas criados são frutos deste idealismo presente neste tipo de teorias de currículo, o qual entra em profunda contradição com a organicidade da realidade presente em Aristóteles. Para ficar mais claro: O que criticamos deste tipo de teoria não é a ideia em si, mas a tentativa de fazer com que uma ideia previamente concebida se encaixe na realidade escolar a qualquer custo.

Ao contrário do que buscou Platão - o qual produziu sua obra com tamanha maestria, a ponto de influenciar nosso pensamento até hoje (CARVALHO, 1994) - muitos pesquisadores atuais - que também se dizem pensadores - querem fazer com que a luta social se torne a essência de tudo. E isso não acontece de forma diferente na área do ensino e do currículo escolar. Dizem eles que o currículo que visa o ensino de algo é opressor, que a escola que ensina é conservadora, que, assim, não haverá mudanças na sociedade, pois, para haver mudanças, as pessoas devem se esforçar para lutar por sua liberdade, que devem pensar por si só e que qualquer ato de transmissão de conteúdos seria quase que como uma maldade. $\mathrm{Na}$ verdade, para eles, os multiculturalistas, os conteúdos não podem nem existir, uma vez que qualquer transmissão dos mesmos seria imposição e imposição, obviamente, é contra a liberdade do indivíduo. 
Pensando de uma maneira quase contrária a isso em relação à escola, acreditamos que deva existir um esforço maior em conservar do que um esforço para lutar. Afinal, o primeiro parece ser até mais exigente. Ao contrário dos multiculturalistas, defendemos que, na atualidade, nossa luta deve ser menor em relação à mudança da realidade do que à conservação da mesma, daquilo que é positivo e eficaz pedagogicamente. A mudança ocorre quase que naturalmente, enquanto a conservação daquilo que é útil e bom exige de nós. Segundo Chesterton (2008, p. 122-123), de certa forma, toda tentativa de conservação:

se baseia na idéia de que, se você abandona as coisas à própria sorte, você as deixa como são. Mas isso não acontece. Se você abandona uma coisa à própria sorte, você a deixa à mercê de uma torrente de mudanças. Se você abandona um poste branco à própria sorte, ele logo será um poste preto. Se você deseja particularmente que ele seja branco, precisa pintá-lo continuamente; isto é, você precisa estar sempre promovendo uma revolução. Em resumo, se você quer o velho poste branco, precisa ter um novo poste branco.

Devemos também deixar claro o seguinte: Não estamos negando o valor das revoluções. De acordo com Souza (1993), as teorias do currículo de cunho crítico ofereceram possibilidades de mudanças significativas através das discussões sob este viés. O que criticamos é o prazer que há em fazer revolução só pela revolução. Criticamos este momento em que vivemos no meio acadêmico, no qual, na ânsia de lutar pelo ideal imaginado, as pessoas esquecem que este é inseparável e impossível se desconsideramos a realidade em que vivemos. Criticamos que, com esta mentalidade estritamente revolucionária pregada pelas pesquisas atuais, em que a luta contra tudo que já estava bem estabelecido é inquestionavelmente necessária, acabamos numa luta sem fim e sem sentido (possibilidade) de mudança. Assim, a luta para derrubar o que estava estabelecido, estabelece-se mais ainda e a única coisa que fica de fato estabelecido é uma guerra (bagunça) generalizada no chão da escola. Segundo Chesterton (2008, p.109) “alguma satisfação é necessária até mesmo para melhorar as coisas.” E, segundo Rosenstock-Huessy, uma revolução, guerra ou conflito é necessário para que não se estabeleça uma apatia em relação àquilo que é nocivo à sociedade, porém a guerra ó tem sentido se visar um futuro acordo de paz, uma futura volta à normalidade das coisas.

Uma guerra termina quando as pessoas voltam a falar umas com as outras; quando tal não se dá, é que a guerra ainda está latente. Um tratado de paz é o início da conversação entre vizinhos territoriais. [...] Para que se chegue a 
ela, é necessário que o fato de as pessoas não falarem umas com as outras tenha alcançado um ponto crítico e gerado uma explosão de violência. [Porém] A guerra já era um passo em direção ao outro, e o conflito, apesar da dor, era também um passo em direção à paz. A vida prefere o sofrimento à indiferença. A guerra seguia-se à ausência de relações e visava ao estabelecimento de relações. Como todo nascimento, a paz tinha de vir à luz pelo trabalho de parto chamado "guerra".(ROSENSTOCK-HUESSY, 2002, p. 54-55)

Acreditamos, portanto, que, hoje, as discussões sobre o ensino e o currículo exigem menos lutas de ordem social, política ou cultural - que têm sua importância - e mais "acordos de paz”, os quais exigirão de nós um esforço de diálogo e vontade para voltar nossos olhos à realidade da escola de fato, aquela que exige tomadas de decisão sobre os fatos, pois o ensino de fato exige que consideremos que os fatos existem.

\subsection{Real e ideal}

Continuemos a discussão partindo do seguinte princípio: Para que um raciocínio seja cada vez mais frutífero, positivo, verdadeiro e, por isso, digno de consideração, é necessário que o mesmo se identifique cada vez mais com a realidade dos fatos. Para Santos (1961, p.19),

Fato é o que se nos apresenta aqui e agora, num lugar, num momento determinado; quer dizer, condicionado pelas noções espaço e tempo. Estar no tempo e no espaço é o que se chama existir. Nós não atribuímos, não emprestamos existência ao fato; ele possui existência.

Com isso, podemos enfatizar a importância do processo dialético (aristotélico), o qual nos proporciona um retorno à realidade, sem o qual muitas pesquisas (estritamente embasadas na lógica) atualmente são desenvolvidas - e, por isso, ao nosso ver, estão comprometidas em sua validade científica (CARVALHO, 1997). Porém, aqui devemos ressaltar que não pretendemos a separação seguida de um total isolamento entre ideal e real. O resultado de uma separação - tal qual a separação entre filosofia e ciência - seria desastroso:

O sábio investigador dos fatos naturais que não tem base filosófica, termina apenas num colecionador de acontecimentos, como o filósofo, que prescinde da ciência, está sujeito a cair num pensamento abstrato e vicioso. (SANTOS, 1961, p. 17) 
Partindo deste princípio - da impossibilidade desta separação - desejamos mostrar que há sim a necessidade de priorizar um em detrimento do outro de acordo com o tempo que atravessamos. Para o melhor entendimento, segue o exemplo de Carvalho (1994, n.p.),:

Quando o arquiteto concebe uma casa, ele concebe com um todo, o esquema geral; mas na hora de construir, tem de seguir a ordem exatamente inversa, tijolo por tijolo. Quando você vê a casa, novamente o que vê é o todo; mas quando vai percorrê-la tem de ir parte por parte. Há uma série de inversões de hierarquia

Atualmente, na maioria das pesquisas acadêmicas, encontramos uma busca de que o real (aquilo de que a existência é passível de percepção sensível, ou seja, aquilo que “enxergamos ao abrir os olhos") se adapte ao ideal ${ }^{1}$ (previamente imaginado). Para nós, esta tentativa é infundada e compromete cada vez mais o desenvolvimento da educação como um todo. Isto não quer dizer que não podemos ter ideais. Pelo contrário, podemos e, enquanto seres humanos, devemos tê-los. Porém, o que criticamos aqui é esta tentativa de fazer com que aquilo que já é deixe de ser mesmo não podendo. Como se o que é real tivesse que deixar de ser real, só porque o mesmo não se adapta ao meu ideal. Isto, com certeza, é um absurdo. Porém, não deixa de ser uma realidade nos textos de alguns pesquisadores.

Se ambos têm valor, a ideia e a realidade, cabe aqui então o questionamento: Por que devemos partir do real (dos fatos presentes na realidade) para alcançar o ideal (aquilo que almejamos) e não do ideal para o real? Primeiro motivo: Ambos são importantes, porém a adequação do real a um ideal é impossibilitada, muitas vezes, pelas próprias condições em que o real se encontra, o que pode gerar revolta ou frustração por parte daquele que desejava mudar o real em vista de um ideal imaginado. Segundo motivo: O que temos é o real e o que buscamos é o ideal. Porém, só é possível alcançar o ideal se consideramos o real. Este serve de sustento para a busca daquele. Terceiro motivo: Como ainda não chegamos ao estado ideal das coisas não temos plena certeza que o ideal que imaginamos ser o estado ideal das coisas é, de fato, algo positivo, capaz de promover desenvolvimento. Prova disso é a possibilidade de engano, que é um elemento auto-evidente em todo ser humano.

\footnotetext{
${ }^{1}$ Entendemos o conceito de ideal de acordo com o Dicionário de Santos (1963): Ideal - a) O que pertence às ideias, sob todas as suas acepções; b) $\mathrm{O}$ meramente mental; c) $\mathrm{O}$ que possui o caráter de satisfazer completamente uma aspiração, um desejo, um querer; d) Uma norma de vida, uma meta que se deseja alcançar, que seria a plenitude se fosse atingida, mas que se pode conceber como inatingível; e) $\mathrm{O}$ contrário da vida meramente utilitária, mas da atitude de nobre elevação estética, ética, social para com a vida, e as coisas da vida; f) Empregado também no sentido de perfeição.
} 
Na melhor das utopias, devo estar preparado para a queda moral de qualquer homem de qualquer posição a qualquer momento; devo estar preparado especialmente para minha queda de minha posição neste momento. (CHESTERTON, 2008, p. 127)

Para ficar mais clara esta questão: Posso estar enganado ao querer que o ideal que imaginei para a sociedade deva se aplicar agora, uma vez que as condições que a sociedade me apresenta agora me mostram que só o fato de enunciar meu ideal promoveria sentimentos como indiferença ou revolta, conflitos estes que poderiam ser amenizados ou evitados se, mantendo meu ideal, eu promovesse um trabalho no real que "preparasse o terreno" para uma maior aceitação deste mesmo ideal. A seguinte comparação do mesmo autor acima citado ilustra melhor este raciocínio: "Como podemos correr se estamos, talvez, à frente do nosso tempo? Como podemos correr para pegar um trem que talvez não chegue antes que se passem alguns séculos?" (CHESTERTON, 2008, p. 116).

\subsection{Condições e condicionado}

Mencionamos algumas vezes acima o termo condições. Devemos deixar claro também que considerar as condições de um dado contexto real não significa e não está diretamente ligado com a questão do condicionado ${ }^{2}$. Enquanto este se refere à categoria de dependência, aquele se refere à capacidade/possibilidade de favorecimento. São diferentes. Condição, para nós, diz respeito aos fatores da realidade que favorecem a causa de certos fatos,

A condição é o que favorece a causa a produzir o efeito. Assim se o vento que passa por uma janela apaga uma vela, o apagar desta é causado pelo vento; a janela aberta foi a condição. Em filosofia dever-se-ia empregar este termo apenas neste sentido, a fim de se evitarem as confusões que daí decorrem. (SANTOS, 1963, p. 354)

Esta delimitação minuciosa é necessária, pois, em hipótese alguma, a tese defendida por este artigo se refere - ao ressaltar a importância das condições do contexto - à ideia de condicionado ou ao relativismo. Este, à medida que nega a inexistência absoluta de qualquer universal, nega seu próprio significado, pois o caráter absoluto implica universalidade. Desta forma, segundo Carvalho (1999, n.p.), “o relativismo estaria ele próprio relativizado e

\footnotetext{
${ }^{2}$ Segundo Santos (1963, p.354), condicionado significa "a dependência de alguma coisa a outra quanto a seu ser." Daí o termo Filosofia do Condicionado, o qual se refere à filosofia relativista. 
acabaria se resumindo numa platitude sem qualquer significado filosófico", pois negar a possibilidade da universalidade impossibilita até mesma essa negação e, assim, a invalida.

Podemos dizer então que, ao pensar sobre o currículo escolar, devemos nos atentar aos diferentes contextos em que se configuram, porém dizer que os conteúdos - elemento central do ato de ensinar (FORQUIN, 1993; SAVIANI, 2000; GIMENO, 2000) - devem emergir desta diferença é se aproximar do relativismo e isso não é desejável aqui. Quando falamos de diferença de contexto de atuação profissional, nos referimos ao caráter prático da educação escolar e não ao princípio dos conteúdos, os quais são universais e só terão sentido positivo se assim o for. A questão levantada até aqui se resume à seguinte proposição: Os conteúdos universais devem ser ensinados e a devida atenção às diferenças de contexto não inviabiliza este ensino, pelo contrário, proporciona meios para que este ato de ensinar seja mais eficaz. As diferenças de contextos são de ordem estritamente prática. Prova desta proposição é o fato de que há também inúmeras semelhanças entre os diversos contextos de atuação. Estes não poderiam ser tão diferentes a ponto de interferir nos princípios fundamentais (na essência) da educação, os quais se baseiam, como já enunciamos - e é necessário enfatizar - na ideia de ensino dos conteúdos universais.

\subsection{Movimento: Da potência para ao ato}

Aqui apresentamos outro princípio de cunho aristotélico - sobre o movimento como passagem da potência para o ato (REALE; ANTISERI, 2007) - que clarifica[m] ainda mais estas distinções já realizadas - e por aqui encerramos a análise, a qual poderia prosseguir: A existência de fatos não anula a possibilidade de mudança - ou de movimento, para ser fiel aos termos utilizados por Aristóteles. As coisas, de certa maneira, mudam. Existe aqui um caráter de relatividade. Porém, porque mudam não podem, automaticamente deixar de ser o que foram, são e sempre serão. Portanto, há algo nas coisas que não muda. Então, as coisas mudam ou não? Eis o princípio que resolve esta aparente contradição: As coisas tem a capacidade de mudar (potência), mas não perdem, por isso, sua substância (continuam existindo em ato, o que possibilita qualquer mudança). Ou seja, a possibilidade de mudança não impede que elas existam em ato. Segundo Santos, "o que tem a possibilidade de vir a ser já é” (SANTOS, 1961, p. 37).

O que muda nas substâncias são os acidentes (aparências), não a essência. Segundo Santos (1961), para Aristóteles, os caracteres essenciais e acidentais compõem a totalidade da 
substância. Por exemplo, o fato de uma criança mudar sua aparência, (acidente) ao crescer e se tornar um adulto, evidencia uma mudança, um movimento - a criança, por ser criança, é potência, enquanto tem a possibilidade de se tornar adulto - o que não interfere na essência da pessoa que cresceu, ou seja, naquilo que substancialmente a pessoa foi, é e será. Deste princípio, podemos concluir o seguinte, concordando com Santos (1961, p. 25)

O homem em face da realidade percebe que esta não é homogeneamente igual. Ela apresenta diferenças [...] Mas essas diferenças são intensivamente maiores ou menores, pois uma pedra e outra pedra apresentam menores diferenças que uma pedra e um rio.[...] O que há na natureza, o que se apresenta ao homem, tem caracteres que se assemelham. Como poderia viver o homem se cada experiência fosse sempre um nova experiência?

Voltando ao caso que estamos discutindo (da diferença entre contextos de atuação e da essência do ensino): As condições do contexto de atuação profissional interferem ${ }^{11}$ nas práticas pedagógicas adotadas neste mesmo contexto. Dito de outra forma: As condições de um contexto favorecem a diferenciação das práticas em relação a outro contexto. Ou melhor ainda, as condições do contexto favorecem mudanças (movimento) das práticas. De acordo com a terminologia de Aristóteles: As práticas, neste caso, são a substância e as condições do contexto são a causa eficiente da mudança, pois possibilitam que um ato de ensino seja alterado, passando de potência (possibilidade de se transformar) em os atos de ensinar diferenciados entre si.

Para ficar mais claro, pensemos no exemplo: Se me proponho a ensinar os alunos a jogar peteca, me deparo com várias possibilidades de ensinar a jogar peteca. A escolha da forma de ensinar, neste caso, é relativa ao contexto. Daí a causa de que, se comparados, os atos de ensinar de diferentes contextos sejam "aparentemente" 3 diferentes. Em cada contexto, haverá diferenças nas estratégias de se ensinar jogar peteca. Porém, ensinar jogar peteca, independentemente do contexto em que se aplica, será ensinar jogar peteca, porque a função do ato de ensinar jogar peteca em qualquer parte do mundo é fazer com que aqueles que se beneficiam deste ato aprendam a jogar peteca.

\footnotetext{
3 Aparência do ato de ensinar está relacionada à ideia de estratégias de ensino. O professor, de acordo com o contexto que atua, adota determinadas estratégias a fim de se adaptar às condições exigidas pelo mesmo. Estas estratégias visam a eficácia do ato de ensinar e, justamente por isso, se diferenciam uma das outras. Portanto, tais diferenças são externas (aparentes), pois não são capazes de alterar a substância do ato de ensinar, uma vez que, o objetivo das mudanças de estratégias é o próprio ensino. Então, neste caso, as estratégias são "acidentais", para concordar com o termo aristotélico.
} 
Sendo assim, a diferença dos atos de ensinar (práticas pedagógicas), de acordo com o princípio enunciado acima, não dizem respeito à essência do ato de ensinar em si e sim ao seu acidente, ou seja, às mudanças externas deste ato, que continuará sendo ato, porque foi, é e nunca deixará de ser, a não ser que queiram (violentamente) mudar sua essência, como almejam os relativistas e multiculturalistas, transformando-o em outra coisa que não é mais o ato de ensinar, pois não é mais portador do gênero que permita o definir como ensino. Para ficar mais claro: A essência do ato de ensinar está intimamente relacionada ao favorecimento, à transmissão, à perpetuação - seja lá o que for o nome que queiram dar - dos conteúdos universais aos que se beneficiam do mesmo ato. Perdida esta essência, o ato de ensinar perderia seu caráter de ensino pois teria deixado de ser eficaz em sua função (FORQUIN, 1993; SAVIANI, 2000). Logo, as condições do ambiente escolar favorecem uma mudança no nível da prática pedagógica, não da função da escola - ou seja, da transmissão dos conteúdos universais, como essência do ato de ensinar. De certa forma, a argumentação realizada aqui vai ao encontro da seguinte afirmação de Chesterton (2008, p. 42) - a qual não deixa de ser engraçada:

No momento em que se entra no mundo dos fatos, entra-se no mundo dos limites. Pode-se libertar as coisas de leis externas ou acidentais, mas não das leis da sua própria natureza. Você pode, se quiser, libertar um tigre da jaula; mas não pode libertá-lo de suas listras. Não liberte o camelo do fardo de sua corcova: você o estaria libertando de ser um camelo. Não saia por aí feito um demagogo, estimulando triângulos a libertar-se da prisão de seus três lados. Se um triângulo se libertar de seus três lados, sua vida chega a um desfecho lamentável.

\subsection{Experiência particular como fundamento do conhecimento}

Assim discorre Aristóteles em sua obra sobre a metafísica:

Pois bem, para os fins da atividade prática, a experiência não parece diferir em nada da arte; ao contrário, os empíricos saem-se até melhor do que aqueles que possuem a teoria sem a prática. E a razão está no seguinte: A experiência é conhecimento dos particulares, enquanto a arte é conhecimento dos universais; Ora, todas as artes e as produções se referem ao particular: Com efeito, o médico não cura o homem a não ser por acidente, mas cura Callias ou Sócrates ou qualquer outro indivíduo que leva um nome como estes, ao qual, justamente, acontece ser homem. Portanto, se alguém possui a teoria sem a experiência e conhece o universal mas não conhece o particular que nele está contido, mais vezes errará a cura, porque aquilo a que se dirige a cura é, justamente, o indivíduo particular. (REALE; ANTISERI, 2007, p. 236) 
Concordando com esta afirmação de Aristóteles sobre a arte - que nos remete à imaginação, ao ideal - e a experiência - que, por sua vez nos remete aos dados sensíveis e particulares, ao real - não estamos negando a imprescindibilidade dos universais, tal como os relativistas o fazem. Estamos sim, ao mesmo tempo em que defendemos inseparabilidade destes aspectos (ideal e real) - como o próprio Aristóteles defende (CARVALHO, 1996) reafirmando a imprescindibilidade dos particulares, os quais nos permitem compreender melhor a realidade a fim de mudá-la e conduzi-la ao ideal, o qual, por sua vez é da ordem dos universais. Defendemos, portanto, a necessidade de olhar para a realidade não como única possibilidade de uma investigação honesta, mas como única possibilidade de devolver a honestidade às investigações que esqueceram a realidade. Segundo Carvalho (1996, p. 124), para Aristóteles, o conhecimento é como uma árvore cujas raízes são a própria realidade. Sendo assim,

temos de admitir que a vida do conhecimento humano não pode cortar jamais suas raízes e encerrar-se num sistema demonstrativo, sem que este sistema, no mesmo ato, esteja condenado a não abranger senão os planos mais gerais e abstratos da esfera das coisas conhecidas e que, deste modo, deixe de ser conhecimento efetivo para se tornar apenas fórmula de um conhecimento possível, a efetivar-se, justamente, no retorno às coisas singulares que os sentidos nos oferecem.

Assim como não se atentam a uma comparação como esta, muitos pesquisadores, atualmente, esquecem-se também das seguintes verdades: Em minha imaginação, tudo pode acontecer. Mas, na realidade, nada do que aconteceu deixará de ter acontecido, mesmo que eu queira muito, pois a realidade é aquilo que é independentemente da minha vontade. Chesterton (2008, p.69) expressa este princípio da seguinte maneira: "O ser humano pertence a este mundo antes de começar a perguntar se isso é agradável.”.

Os fatos individuais revelam a realidade. E desconsiderar os fatos individuais é abandonar a única certeza que temos enquanto indivíduos, a partir da qual poderíamos raciocinar. Eis outro grande princípio: Quando queremos abranger mais coisas, inevitavelmente, perdemos seus pormenores (SANTOS, 1961). Atualmente chegamos a um nível de abstração tão grande nos discursos acadêmicos que, muitas vezes, por se perder de vista a realidade através de abstrações lógicas, alguns passam até a desconsiderá-la como se nunca tivesse existido. Sonham.

O sábio, no sentido aristotélico, não é aquele que se elevou ao céu das essências platônicas, mas aquele que, retornando das alturas, sabe ir reconhecendo, na variedade das coisas sensíveis que se lhe apresentam no espaço e no tempo, o princípio de unidade que nelas se insinua.(CARVALHO, 1996, p. 124) 
Segundo Rosenstock-Huessy (2002, p. 112): “A lógica de qualquer sentença abstrata demanda que ela seja precedida de dados concretos e específicos. Nenhuma sentença abstrata é verdadeira sem tais antecedentes, sem tais dados concretos as afirmações abstratas". Estas "não fazem sentido senão em conexão com as conclusões de afirmações concretas reais, que datam os fatos" (p.114). E, da seguinte forma, este mesmo autor conclui:

não se pode chamar pensador a um homem só porque ele consegue pensar "logicamente" em termos acadêmicos; para tanto, ele tem de ter participado de processos pelos quais a vida é produzida. De outro modo, nunca saberá quando as "coisas" estão suficientemente mortas para submetê-las a um tratamento abstrato. Hoje, diz-se a milhões de pessoas que elas podem "pensar" a respeito do mundo, da humanidade e da paz em geral. Mas não se lhes diz que ninguém pode pensar se não souber, por experiência própria, cumprir uma promessa, compartilhar as alegrias e tristezas de uma comunidade, e narrar um acontecimento com respeito e simpatia, como alguém que com ele se pode identificar. (p.115-116)

\section{CONCLUSÃO}

Busquemos fugir desta abstração exacerbada: Partamos da realidade, ponhamos nossos pés neste terreno sólido e individual da realidade (isto sinaliza a dialética). Sem perder a esperança que um dia possamos alcançar mudanças satisfatórias, busquemos dar passos, "acordados". Se não alcançarmos a tão sonhada meta, pelo menos não envelheceremos parados no mesmo lugar onde adormecemos e passamos apenas a sonhar. Os fatos revelam uma realidade, a qual deve ser aceita, pois nossa vontade (ideal), unicamente, não é capaz de mudar o real. O que pode mudar o real é nossa vontade em encarar os fatos reais como reais. Aí está a grande possibilidade de mudança: “O homem que vai melhorar o lugar é aquele que o ama sem uma razão" (CHESTERTON, 2008, p. 73).

Para que os estudos sobre currículo promovam ações mais eficazes é necessário passarmos a considerar, cada vez mais, o contexto de atuação profissional. Tal consideração torna-se imprescindível à medida que faz parte dos fundamentos, sem os quais qualquer ação pedagógica, por mais que tenha aparentes bons ideais, torna-se vulnerável devido ao afastamento dos alicerces da realidade sensível que os fatos ligados ao contexto de atuação profissional evidenciam. Devemos nos atentar, portanto, à medida que consideramos as condições que o contexto oferece, às estratégias de ensino, as quais devem visar a maior eficácia possível do mesmo ensino, o qual, por sua vez, com isso, não perde sua essência, ou 
seja, a necessidade da transmissão de conteúdos, como função essencial da escola. Portanto, por mais que considerar as condições do contexto seja algo importante para o ensino (pois o torna mais eficaz), tais condições são (e sempre serão), essencialmente, menos importantes que o próprio ensino. Considerar a realidade ou as condições do ambiente escolar é imprescindível, pois a escola é um lugar marcado pela complexidade de relações, o que nos desafia. O desafio que o ensino nos propõe é grande e seu tamanho deve ser considerado, porém considerar o tamanho de um problema não poderá nunca nos impedir de enfrentá-lo! Desta forma, encerramos com esta bela comparação de Chesterton (2008, p. 121)

\begin{abstract}
Se nossa vida realmente quiser ser bela como um conto de fadas, devemos nos lembrar de que toda a beleza de um conto de fadas está no seguinte: que o príncipe tem um espanto que quase chega a ser medo. Se ele temer o gigante, será o seu fim; mas também se ele não se sentir atônito diante do gigante, será o fim do conto de fadas. A questão toda depende de ele ser ao mesmo tempo suficientemente humilde para espantar-se e suficientemente orgulhoso para desafiar.
\end{abstract}

\title{
REFERÊNCIAS
}

ARROYO, Miguel Gonzalez. Currículo, território em disputa. 2. ed. Rio de Janeiro: Vozes, 2011a, 375 p.

CARVALHO, Olavo de. Aristóteles em nova perspectiva: Introdução à teoria dos quatro discursos. 1. ed. Rio de Janeiro: Topbooks. 1996. 196 p.

O Imbecil Coletivo: Atualidades Inculturais Brasileiras. 7. ed. Rio de Janeiro: Faculdade da cidade editora.1997, 426 p.

O problema da verdade e a verdade do problema. Seminário de filosofia. 20 mai. 1999. Disponível em < http://www.olavodecarvalho.org/apostilas/problema_verdade.html>. Acesso em 01 mai. 2015.

Pensamento e atualidade de Aristóteles. Seminário de filosofia. 15. mar. 1994. Disponível em: <http://www.olavodecarvalho.org/apostilas/pensaris1_1.htm>. Acesso em 01 mai. 2015.

CHESTERTON, Gilbert Keith. Ortodoxia. 1. ed. São Paulo: Mundo Cristão. 2008. 174 p.

FORQUIN, Jean-Claude. Escola e Cultura: as bases sociais e epistemológicas do conhecimento escolar. 1. ed. Porto Alegre: Artes Médicas, 1993, 205 p. 
O currículo entre o relativismo e o universalismo. Educação \& Sociedade. Ano XXI, n.73, p. 47-70, dez. 2000. Disponível em: < http://www.scielo.br/cgi-bin/wxis.exe/iah/>. Acesso em: 05 mai. 2012.

GIMENO, José. O currículo: uma reflexão sobre a prática. 3. ed. Porto Alegre: Artmed, 2000, 325p.

GIMENO, José; PÉREZ, Angel. Compreender e transformar o ensino. 4. ed. Porto Alegre: Artemed, 1998. 396 p.

REALE, Giovanni; ANTISERI, Dario. História da filosofia: Filosofia pagã antiga, vol 1. 3. ed. São Paulo: Paulus. 2007. 385 p.

ROSENSTOCK-HUESSY, Eugen. A origem da linguagem. 1. ed. Rio de Janeiro: Record. 2002. $270 \mathrm{p}$.

SANTOS, Mário Ferreira dos. Convite a filosofia e história da filosofia. 5. ed. São Paulo: Logos. 1961. 214 p.

Dicionário de Filosofia e Ciências Culturais. 1. ed. São Paulo: Matese. 1963. 1430 p.

SAVIANI, Dermeval. Pedagogia Histórico-Crítica: Primeiras aproximações. 7. ed. Campinas: Autores Associados, 2000. 122 p.

SILVA, Tomaz Tadeu da. Documentos de identidade: Uma introdução às teorias do currículo. 3. ed. Belo Horizonte: Autêntica, 2011. 156 p.

SOUZA, Rosa Fátima de. A produção intelectual brasileira sobre currículo a partir dos anos 80. Brasília: Em Aberto, p.117-128, 1993. Disponível em:

< http://emaberto.inep.gov.br/index.php/emaberto/article/viewFile/863/775>

TARDIF, Maurice; LESSARD, Claude. O trabalho docente: elementos para uma teoria da docência como profissão de interações humanas. 7. ed. Petrópolis: Vozes, 2012, 317 p. 